\title{
Phylogenetics of the endemic genus Stemonoporus Thw. (Dipterocarpaceae)
}

\author{
S.C.K. Rubasinghe ${ }^{1}$, D.M.D. Yakandawala ${ }^{2^{*}}$ and D.S.A. Wijesundara ${ }^{3}$ \\ 1 Postgraduate Institute of Science, P.O. Box 25, University of Peradeniya, Peradeniya. \\ 2 Department of Botany, Faculty of Science, University of Peradeniya, Peradeniya. \\ 3 Royal Botanic Gardens, Peradeniya.
}

Revised: 02 June 2008 ; Accepted: 28 July 2008

\begin{abstract}
Stemonoporus Thw. is the most species-rich (27 species) endemic dipterocarp genus in Sri Lanka. All its members are categorized as highly threatened or threatened in the IUCN Red Data Book. The existing classifications of the genus are primarily based on traditional taxonomic methods using a limited number of collected material and sometimes mainly on herbarium specimens. A recent study carried out in order to evaluate the species limits of Stemonoporus strengthens its position as the most species-rich endemic dipterocarp genus in Sri Lanka. However, there are no phylogenetic studies being carried out on this important genus.
\end{abstract}

The aim of the study was to construct the phylogeny of the genus Stemonoporus, using morphological and phytochemical data. Specimens of all representative taxa were sampled from different geographical locations. A total of 170 specimens were collected and six individuals per taxon were examined. Cladistic analysis was performed based on morphological and phytochemical data extracted from specimens collected from different geographical locations and herbarium specimens.

Combined analysis of morphological and phytochemical data suggests that all the species except for Stemonoporus wightii form a monophyletic group with strong bootstrap support of $82 \%$. The strict consensus tree of the combined analysis identifies eight monophyletic groups within the genus Stemonoporus. S. wightii was resolved as the basal taxon of the genus. The identified 27 species are supported as monophyletic groups.

Keywords: Dipterocarpaceae, morphological data, phylogeny, phytochemistry, Stemonoporus.

\section{INTRODUCTION}

Despite the relatively small size of 65,000 square kilometers, Sri Lanka harbours over 4,100 flowering plant species where over a quarter of these species are considered endemic to the country ${ }^{1}$. Notwithstanding the relatively small size, Sri Lanka has a varied climate and topography, which has resulted in a rich biodiversity and today the island is considered one of the most biologically diverse areas in South Asia. Dipterocarpaceae, which forms a very closely-knit family, exhibits high endemism in Sri Lanka. Stemonoporus Thw. is the most species-rich endemic dipterocarp genus in Sri Lanka ${ }^{2}$, and is of special interest with its unique characteristics and vulnerable position. All its members are categorized as highly threatened or threatened in the IUCN Red Data Book ${ }^{3}$ (Table 1). Most species are locally known as mendora, ugudu hal, gulu mora and hora wel in different parts of the country. The distinctive feature of Stemonoporus is the stamens that form a distinctive cone-like structure around the style (Figure 1). The significance of the name is due to its anther with a false pore (pseudo-monoporus) (Figure 2). General morphology of Stemonoporus is illustrated in Figure 3.

All members of the genus are confined to the wet zone of the country, from Knuckles in the north region to Rakwana in the east with the exception of $S$. acuminatus which occurs in Badulla district in the Intermediate Zone (Figure 4). They occur in small or large gregarious groups along streams, always in the wettest parts. Each species has its own well-defined habitat, and geographical and ecological range. They occur upto $1800 \mathrm{~m}$, the highest altitude recorded for any dipterocarp species in Sri Lanka ${ }^{2}$, ${ }^{4}$. Recent investigations revealed that the Stemonoporus habitats are very disturbed either due to deforestation or degradation and therefore most species occur in localized 
patches. Many places that would have been "wet and wettest parts" ten years back have changed with time. Very little regeneration was observed with many species; except in well protected sites such as Sinharaja and Kanneliya forests.

Table 1: The author citations, acronyms and convervation status of different Stemonoporus species. E - Endangered; V - Vulnerable; I - Indeterminate; T - Threatened (1993 Provisional List); HT - Highly Threatened ; TR Threatened (IUCN, 2000).

\begin{tabular}{|c|c|c|c|c|}
\hline \multirow[t]{2}{*}{ Name code } & \multirow[t]{2}{*}{ Species } & \multicolumn{2}{|c|}{ Conservation status } & \multirow[b]{2}{*}{ National List } \\
\hline & & Global & Provincial List 1993 & \\
\hline ST 01 & S. canaliculatus Thw. & $\mathrm{V}$ & & TR \\
\hline ST 02 & S. affinis Thw. & E & $\mathrm{T}$ & HT \\
\hline ST 03 & S. petiolaris Thw. & I & $\mathrm{T}$ & HT \\
\hline ST 04 & S. gracilis Kosterm. & & & HT \\
\hline ST 05 & S. elegans (Thw.) Alston. & $\mathrm{E}$ & & \\
\hline ST 06 & S. cordifolius (Thw.) Alston. & & & $\mathrm{TR}$ \\
\hline ST 07 & S. gardneri Thw. & & & HT \\
\hline ST 08 & S. rigidus Thw. & I & $\mathrm{T}$ & HT \\
\hline ST 09 & S. revolutus Trimen ex. Hooker $\mathrm{f}$. & & & TR \\
\hline ST 10 & S. nitidus Thw. & I & $\mathrm{T}$ & HT \\
\hline ST 11 & S. wighitii Thw. & V & & $\mathrm{TR}$ \\
\hline ST 12 & S. reticulatus Thw. & E & $\mathrm{T}$ & $\mathrm{TR}$ \\
\hline ST 13 & S. oblogifolius Thw. & I & $\mathrm{T}$ & HT \\
\hline ST 14 & S. kanneliyensis Kosterm. & & & HT \\
\hline ST 15 & S. acuminatus (Thw.) Beddome. & $\mathrm{V}$ & & $\mathrm{TR}$ \\
\hline ST 16 & S. marginalis Kosterm. & & & HT \\
\hline ST 17 & S. bullatus Kosterm. & & $\mathrm{T}$ & HT \\
\hline ST 18 & S. moonii Thw. & $\mathrm{E}$ & $\mathrm{T}$ & HT \\
\hline ST 19 & S. latisepalum Kosterm. & & & HT \\
\hline ST 20 & S. scalarinervis Kosterm. & & & HT \\
\hline ST 21 & S. lancifolius (Thw.) Ashton. & $\mathrm{E}$ & & HT \\
\hline ST 22 & S. lanceolatus Thw. & I & $\mathrm{T}$ & HT \\
\hline ST 24 & S. gilimalensis Kosterm. & & & HT \\
\hline ST 25 & S. leavifolius Kosterm. & & & HT \\
\hline ST 26 & S. angustisepalum Kosterm. & & & HT \\
\hline ST 27 & S. scaphifolius Kosterm. & & & HT \\
\hline
\end{tabular}
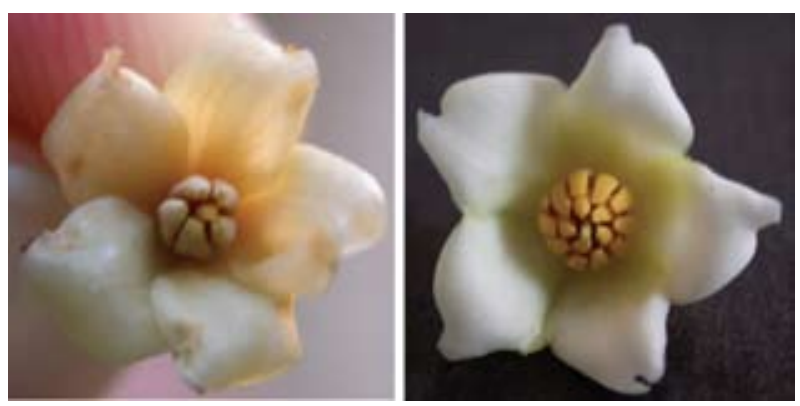

Figure 1: The stamens of Stemonoporus form a characteristic conelike structure around the ovary with $10-15$ or 5 stamens.

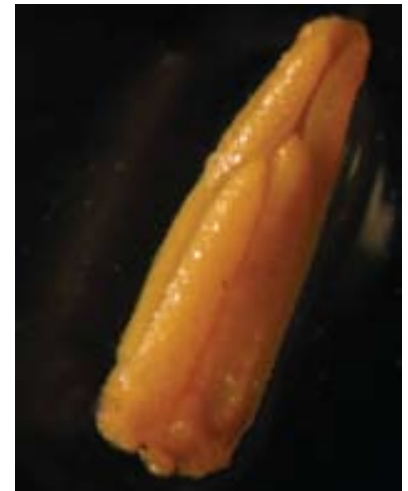

Figure 2: The pseudo-monoporus anther of Stemonoporus: the margins of the two valves touching in one place, where the margin bulges, forming a long oblique orifice apically and a straight one below the bulges. 


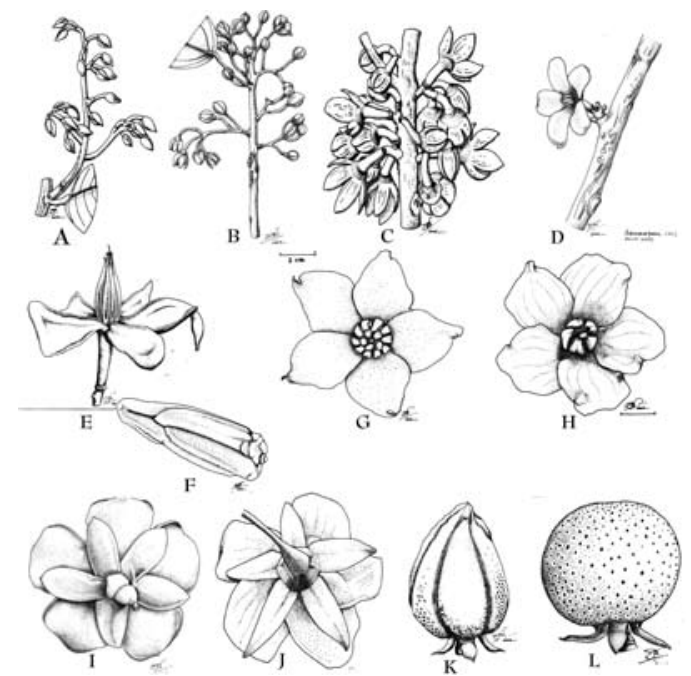

Figure 3: General morphology of Stemonoporus Thw.

Key: panicle of $S$. wightii (A), panicle of $S$. gardneri (B), condensed raceme of $S$. oblongifolius (C), solitary flower of S. scalarinervis (D), conspicuous cone-like structure formed by the stamens of $S$. elegans (E), filament of $S$. elegans (F), flower with 15 stamens $S$. gardneri (G), flower with 5 stamens $S$. cordifolius $(\mathrm{H})$, imbricate aestivation of sepals of $S$. bullatus (I), and valvate aestivation of sepals of S. gardneri (J), cone shape fruit of ST $23(\mathrm{~K})$ and sub-spherical shape fruit of $S$. bullatus (L).

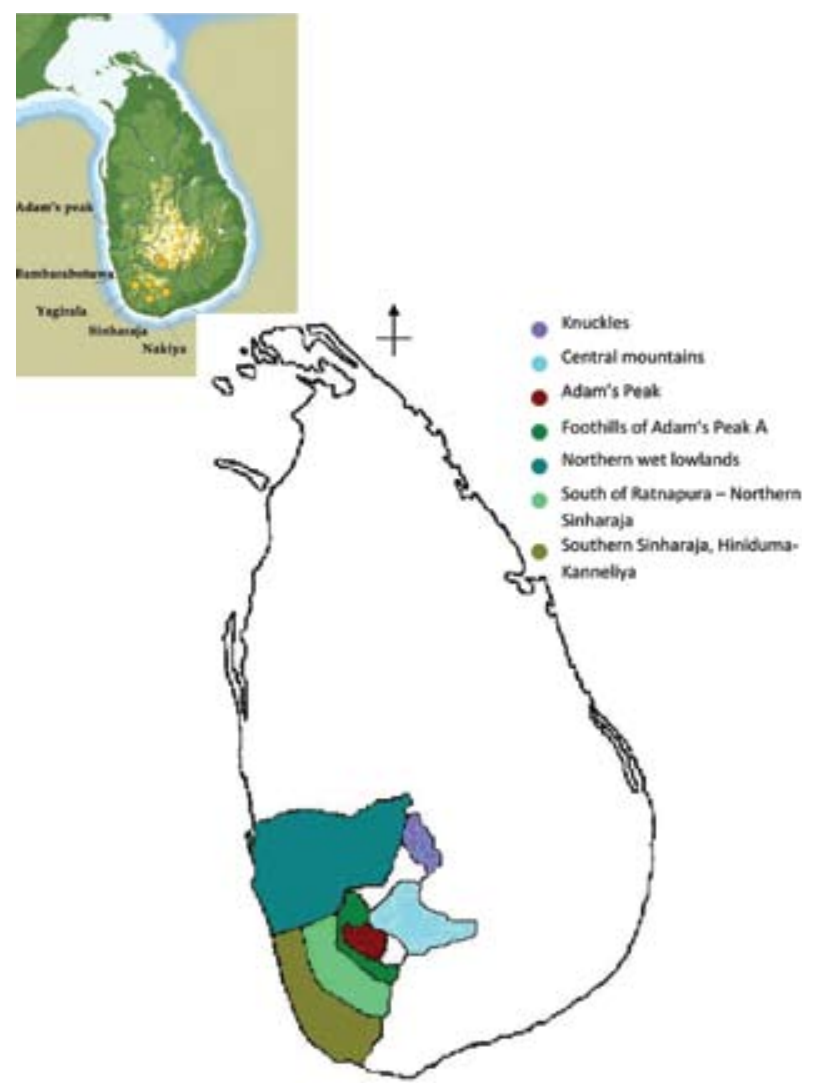

Figure 4: General distribution of Stemonoporus Thw.

\section{Taxonomic history}

The genus was first recognized by Thwaites in 1854 by recognizing 11 species of Stemonoporus and 3 species under Monoporandra ${ }^{2}$. Thwaites in the Addendum ${ }^{5}$ referred them all to Vateria under the influence of Bentham further adding 3 new species making a total of 15 'proper' Stemonoporus species. A. de Candolle in 1868 reduced Stemonoporus to Vatica, but kept Monoporandra separate enumerating the same number (15) under Vatica2 ${ }^{2}$. Dyer (1874) reduced Monoporandra lancifolia to a variety of Vateria (Stemonoporus) nitida, recognizing a total of 14 species $^{2}$. In 1893, Trimen in his treatment of Dipterocarpaceae in volume I (1893) of his Handbook to the Flora of Ceylon separated Stemonoporus from Vateria ${ }^{6}$. He described 13 species in Stemonoporus and 2 in the reinstated genus Monoporandra ${ }^{6}$. Hooker (1990) added (in the 5th volume of Trimen's Flora in 1900 , two more species, of which one (Stemonoporus lewisianus) was referred by Alston (1929) to Vateria, followed by Livera (1924). Ashton ${ }^{4}$ included this under Cotylelobium, which was finally reinstated by Kostermans (1992) as Vatica, which brings the number to 16 species. Alston (1929) in his supplement to Trimen's Flora (volume VI) in 1931, included Monoporandra Thw. in Stemonoporus, restored Stemonoporus lancifolius but failed to recognize $S$. moonii, and hence has still only 15 species $^{2}$. Ashton ${ }^{4}$, in his treatment on the family in the Revised Flora of Ceylon ultimately restored $S$. lancifolius, but excluded $S$. moonii and hence has still only 15 species. The most recent treatment of the family Dipterocarpaceae by Kostermans ${ }^{2}$ recognizes 26 species within the genus Stemonoporus, where the genus is broadly divided into two sub-genera (Monoporandra and Stemonoporus) based on the number of stamens, and no further taxonomic studies on Stemonoporus have been conducted to date.

Notwithstanding the recent revision of the Sri Lankan Flora ${ }^{4}$, several ambiguities exist with the species limitations in the genus Stemonoporus. All existing classifications of the genus including the one in the revision of the Sri Lankan Flora are based on traditional taxonomic methods derived from a few vegetative characters. Even the most recent treatment of the family Dipterocarpaceae by Kostermans ${ }^{2}$ is based on morphological data using conventional methods which are mostly based on intuition, and therefore are not reproducible. Further, no phylogenetic studies have been carried out on Stemonoporus. Such a study will answer several important questions on the evolution and also will contribute to the dipterocarp phylogeny within Angiosperms. 
A morphometric analysis carried out during a recent study revealed that the genus consists of 27 morphologically different entities further strengthening its position as the most species rich endemic dipterocarp genus in Sri Lanka7. This study identified all 26 species of Stemonoporus recognized by Kostermans ${ }^{2}$ supporting his treatment of the genus. Further, several additional characters heve been identified based on a large number of specimens to support their species limits. In addition to the existing taxa a new species of Stemonoporus has also been recognized.

\section{Morphological data and plants systematics}

Morphological characters, features of external form or appearance, currently provide most of the characters used for field plant identification and many of those used for hypothesizing phylogenetic relationships. These features have been the foundation for most classification systems and used for a longer time than anatomical or molecular evidence. They have constituted the primary source of taxonomic evidence since the beginnings of plant systematics $^{9,10}$. From the earliest recorded observations of the ancient Greeks, through the age of the herbalists (1470-1670), into the early classifiers such as Ray and Tournefort, then Linnaeus, Jussieu, the Candolles, Bentham and Hooker, and so on to the present systems, morphology has been playing the dominant role ${ }^{10}$.

Plant morphological characters are still the most popular type of characters used in taxonomic studies and they play a major role in taxonomic keys and field taxonomy. They will probably continue to be the main discriminatory feature for both the identification and grouping of plants mainly due to the fact that they are readily recognizable and easily described.

\section{Phytochemistry and plant systematics}

The task of a taxonomist is rendered very difficult by relatively rapid divergences of characters and taxa in the course of adaptive radiation and by several types of convergence known to occur during taxon evolution. According to chemotaxonomists, inevitably all existing systems of classification are imperfect, and chemical characters may be very helpful ${ }^{11}$.

The major application of chemical data in practical taxonomy has been as an aid in revision where the available biological characters are ambiguous or conflicting in their distribution ${ }^{12}$. During evolution it may happen that unrelated groups of plants give rise to morphological similarities (convergence). Conversely, related plants may give rise to very dissimilar descendants (divergence). Such phenomena can cause considerable taxonomic ambiguities. In such situations the presence or absence of chemical compounds can contribute to solve problems such as those due to convergence or divergence. The classification of plants is built upon very thorough consideration of many very different biological characteristics. Naturally, it is improbable that a morphological convergence would be accompanied by "chemical divergence". However, taxonomists must always weigh chemical data in balance along with results obtained from many other sources ${ }^{13}$.

Another most obvious application of chemical methods has been in those instances where morphological criteria fail to provide a key to separation ${ }^{12}$. They can also be used to revise and improve existing classifications, and thus gain support for a suggested reclassification ${ }^{14}$.

\section{Phylogenetics}

Knowledge of how organisms are related to one another, coupled with an understanding of their evolutionary history, has increased tremendously in recent decades ${ }^{15}$. Cladistics is the method of classification that groups taxa hierarchically into discrete sets and subsets. These methods were intended for implementing Darwin's concepts of ancestors and descendants and that is to explain the relationships within an evolutionary framework.

The present study was carried out to construct the phylogeny of the genus Stemonoporus and thereby to investigate the monophyly and the internal relationships of the genus, using morphological and phytochemical data. The importance of determining the phylogenetic relationships has been well documented. Elucidating the phylogenetic relationships of Stemonoporus will not only be highly valuable for furthering our knowledge on its species limits, monophyly of the genus and its placement within the family Dipterocarpaceae but will also shed light into the yet unresolved key question on the role of the Deccan Plate in the spread of Southern angiosperms of Gondwanic origin into Laurasia which is of considerable global and regional biogeographic significance ${ }^{8}$. The aseasonal climate in southwestern Sri Lanka sustains a relict rain forest vegetation of the original Deccan Plate. Therefore, phylogenetic research into these endangered relict taxa of historical plant geographic significance using modern phylogenetic techniques is well within the international framework of research on global and regional biodiversity. 


\section{METHODS AND MATERIALS}

In-group sampling: Extensive field studies were made to collect specimens of all representative taxa of the genus Stemonoporus recognized by Ashton ${ }^{4}$ and Kostermans, ${ }^{2}$ from all possible locations. Specimens were collected from the Sinharaja Forest Reserve (Moulawella, Kosgulana), Kanneliya, Hiniduma, Suriyakanda, Morningside, Neluwa-Pelawatta, Peak Wilderness, Moray Estate, Gilimale, Bambarabotuwa, Knuckles, Kitulgala, Bulatsinhala, Balangoda, Dotalugala and Horagolla Kele.

Out-group sampling: Polarity of a character refers to the evolutionary direction of the character. Many methods and criteria for assessing the evolutionary direction of characters have been proposed and reviewed. Of these, the out-group comparison approach has been adopted in this study; where if a taxon that is not a member of the group of organisms being studied has a character state that is the same as some of the organisms in the group, then that character state is considered to be plesiomorphic.

The genus Vateria copallifera (Retz.) Alston. (Dipterocarpaceae) was used as the out-group. The selection was based on a molecular phylogenetic study using $\mathrm{rbcL}$ sequence data by Dayanandan et al. ${ }^{16}$. Specimens of Vateria copallifera were collected from Sinharaja, Gilimale and Kandy.

Extraction of morphological characters: Leaves, flowers and fruits collected from the in-group and the out-group were surveyed for morphological characters. Characters were selected by reviewing previous work and searching for variations that had not been previously analyzed. Leaves were analyzed in detail for leaf architectural characters. Flowers were preserved in $70 \%$ alcohol and their sepals, petals, stamens, ovary, style and stigma were observed under the light-microscope (Olympus, BH 2) and the stereomicroscope (Leica, 10446322, 2xWD). Twigs with leaves were pressed between papers, treated with alcohol and oven-dried in a folder and studied under the microscope. Leaf architecture (venation), the pattern made by the primary vein (mid vein), and secondary, tertiary and quaternary veins, was coded by clearing leaves using $5 \% \mathrm{NaOH}$ and then staining for observation. Quantitative characters were counted or measured with a ruler, or protractor. Characters were scored to the extent possible from all the collected taxa and also from herbarium specimens based on the collection at the Royal Botanic Gardens, Peradeniya.

Extraction of flavonoid constituents: Flavonoid constituents were extracted from fresh and air-dried leaf material collected from different geographical locations.
Since flavonoids are polyphenols they possess the chemical properties of phenolics; That is they are slightly acidic and therefore dissolve in alkali ${ }^{17}$.

Acid hydrolysis: During acid hydrolysis the flavonoid glycosides are separated from the sugar and form the aglycone. The dried plant leaves were cut into small homogenous pieces. For acid hydrolysis, $25 \mathrm{~g}$ of this air dried leaf samples were weighed and kept in $2 \mathrm{~N} \mathrm{HCl}$ at $100{ }^{\circ} \mathrm{C}$ for $30-45 \mathrm{~min}$. This separates the sugar from the flavonoid. The aglycones were then extracted into ethyl acetate, 2-3 times using a vortex mixturem, in to a watch glass. After that, the extracts were evaporated to dryness in the air.

Separation of flavonoid aglycones: The separation of plant constituents was carried out using Thin Layer Chromatography(TLC). The dried extracts were dissolved in 2 drops (a minimum amount) of ethanol and applied as concentrated spots on Whatman No. 01 chromatography paper (with aluminium as the adsorbent) (8x4) for $1-D$ chromatography against authentic flavonol and flavone markers myricetin, quercetin, kaempferol and apigenin.

Solvents: Butanol-acetic acid Was prepared by mixing n-butanol: acetic acid: water in the ratio of 4:1:5. After equilibration, the supernatant layer constitutes the solvent proper $^{18}$. Forestal was introduced by Bate-Smith ${ }^{19}$ for the separation of the anthocyanidins. It has subsequently proved very useful for the study of other flavonoid aglycones. The solvent was prepared by mixing acetic acid, water and conc. $\mathrm{HCl}(30: 10: 3 \text { by volume })^{18}$. Dilute acetic acid - in this and similar solvents the flavonoid aglycones do not as a rule move from the start line, only those in which the central heterocycle is saturated and in consequence have a non-planar configuration ${ }^{18}$.

The chromatographic paper was developed in four solvents; HOAc (50\% aqueous acetic acid), BAW (n-butanol-ethanol-water, 4:1:5, top layer), Forestal (acetic acid-con. HCl-water, 30:3:10) and $\mathrm{PhOH}$ (phenol saturated with water).

Spot detection: In TLC, compounds are usually detected as coloured or UV-fluorescent spots, after reacting with the chromatographic reagent, used as spray (Harborne, 1998). The flavonoid spectrum is usually determined for a methanol solution of the flavonoid. The spectrum typically consists of two absorption maxima in the ranges 240-285 nm (Band I) and 300-350 nm (Band II) ${ }^{18}$.

Dried papers were viewed under the long-wave (360 $\mathrm{nm}$ ) ultraviolet for spot detection. Aglycones were further confirmed by colour changes with and without $\mathrm{NH}_{3}$ 
vapour (from a bottle of $0.88 \mathrm{NH}_{4} \mathrm{OH}: \mathrm{H}_{2} \mathrm{O}, 1: 1$ ), with the markers. All the spots that appeared under the UV light were marked and the colour changes were noted. Most of the flavone and flavonol glycoside spots appeared as dark/purple spots under UV light and turned yellow, yellowish green or orange in the presence of ammonia vapour.

Coding of characters: The characters were coded by separating the characters into discrete states. The coding method ' $\mathrm{C}$ ' has been adopted in this study ${ }^{20}$. The data matrix was constructed using the MacClade version 3.04 .

Analysis of data - (cladistic analysis): Most parsimonious trees were recovered by PAUP $* 4 \mathrm{~d} 55^{21}$ and the recovered trees were further analyzed using MacClade $3.04^{22}$ on a
Macintosh computer. A heuristic search was performed with the unordered and equal weighting criteria of Fitch parsimony, 100 replicates of random sequence addition and tree bisection-reconnection (TBR) branch swapping with MULPARS (multiple parsimonious trees) in effect, steepest descent on. The initial trees found with equal (Fitch) weights were used as the basis for successive weighting. Ten trees were held for each step. Strict consensus, 50\% majority rule and Adams consensus trees are obtained and branch lengths and tree scores are calculated using ACCTRAN (accelerated transformation optimization). Successive weighting was carried out using the retention index. Re-weighting was continued until the same tree length was obtained in two successive rounds. Bootstrap analysis employed 100 replicates of full heuristic search (random sequence addition, MULPARS

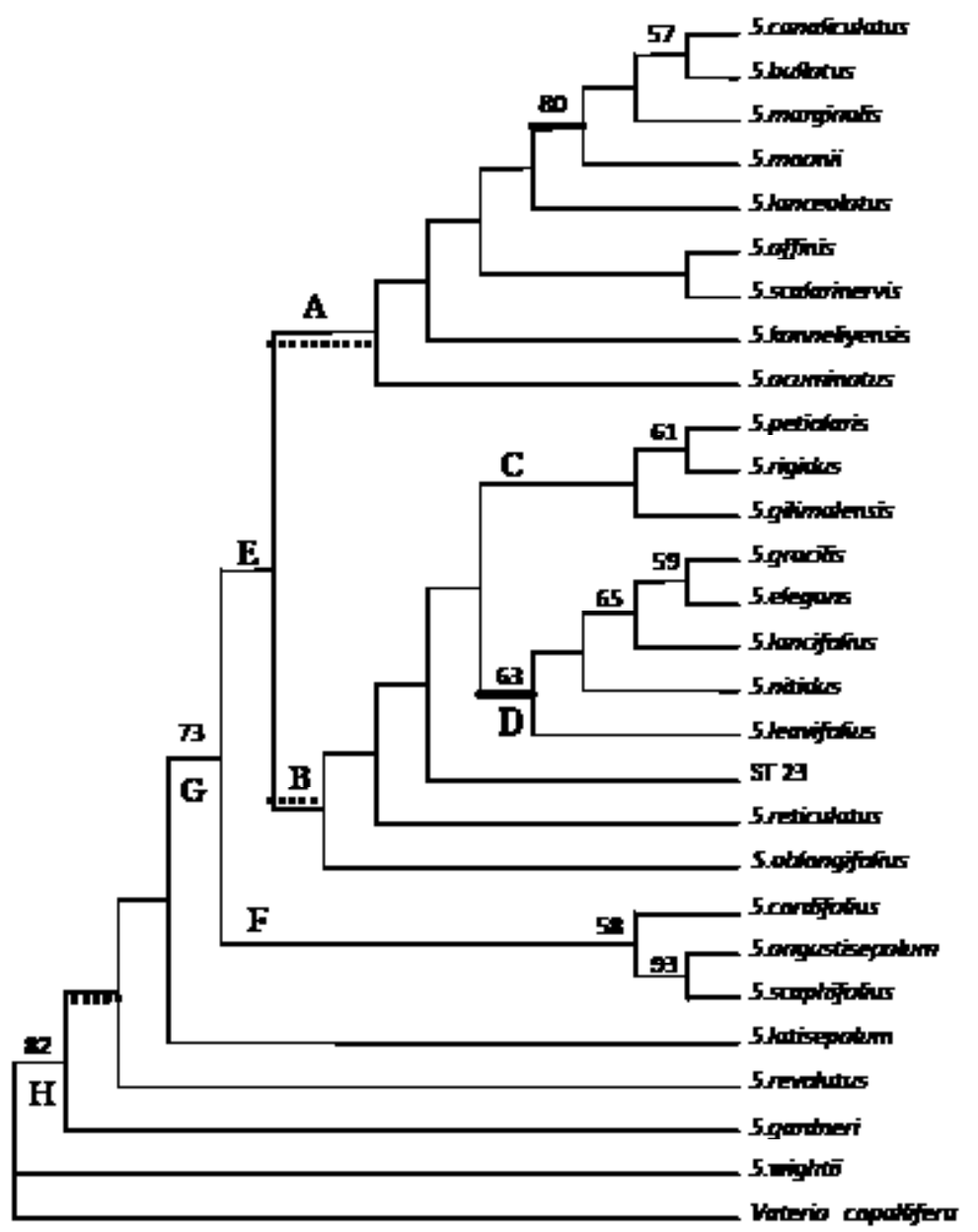

Figure 5: The Strict consensus trees of the two most parsimonious trees recovered during the Fitch Parsimony analysis of the morphological and phytochemical characters. Length $=357, \mathrm{CI}=0.330, \mathrm{RI}=0.911$. The bootstrap support values of over $50 \%$ are shown above branches. The branches that collapse during bootstrap analysis is indicated as dotted lines. The thick branches indicate the distribution of unambiguous synapomorphies. 


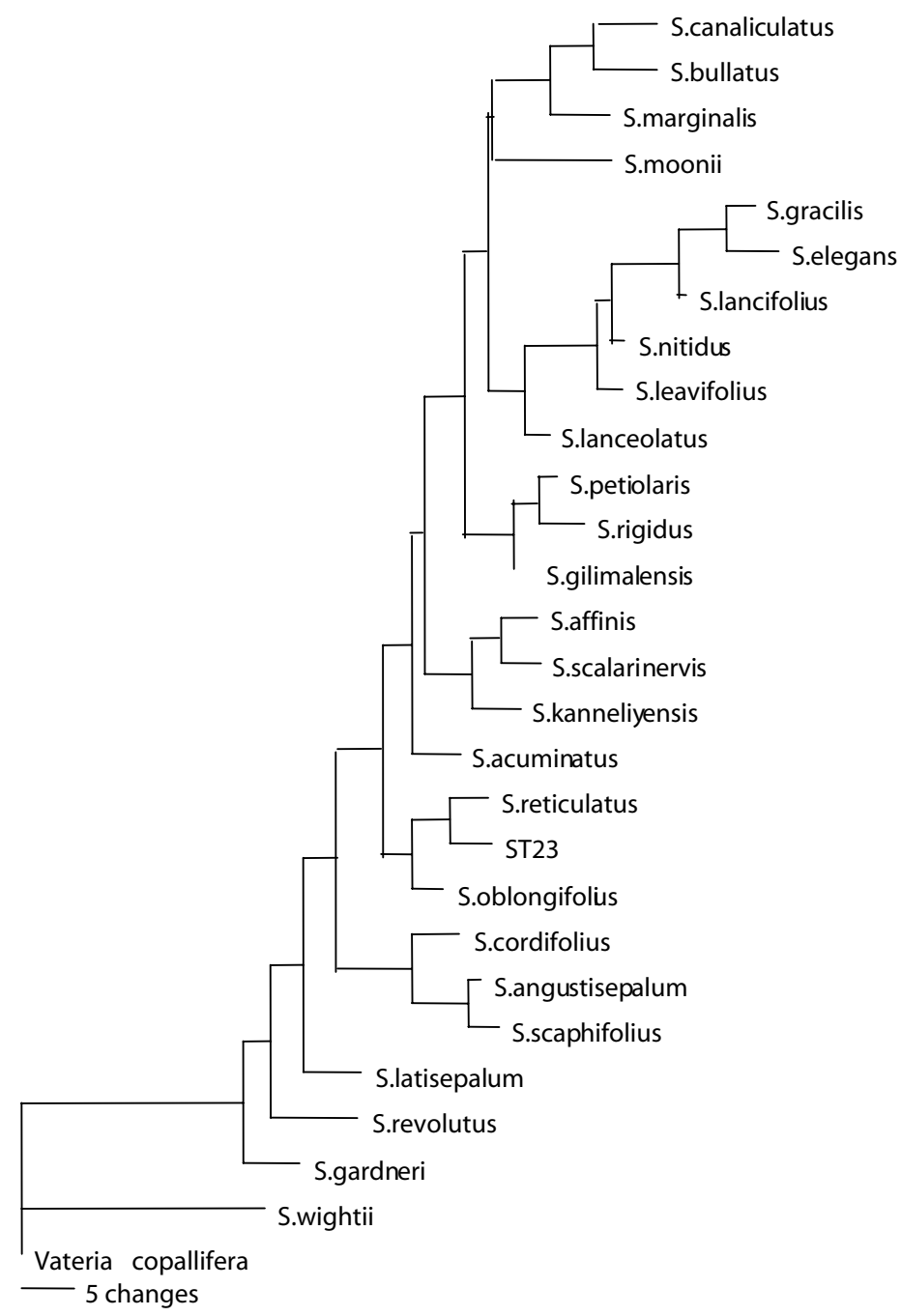

Figure 6: A phylogram recovered during the Fitch Parsimony analysis of the morphological and phytochemical characters

on and steepest descent off), searching with the initially weighted trees and successive weighted trees in order to evaluate the robustness of the clades.

\section{RESULTS}

Combining of morphological and phytochemical data into a single combined data set resulted in a total of 94 characters and character states. Morphological data comprised of a total of 90 vegetative and reproductive characters including both quantitative and qualitative data. The data obtained from the flavonoid aglycone survey is given in Table 2. The list of morphological and phytochemical characters obtained is given in Appendix 1.

\section{Results of cladistic analysis}

Heuristic search under the Fitch criterion of the combined data set yielded a single most parsimonious tree (MPT) of 395 steps with CI (Consistency Index) 0.329 and RI (Retention Index) 0.910. Successive weighting produced two MPTs of 357 steps with a CI of 0.33 and a RI of 0.911 . The successively weighted strict consensus tree is shown in Figure 5. A phylogram recovered during the combined analysis is shown in Figure 6.

\section{Phylogenetic relationships within the genus Stemonoporus}

Combined analysis of morphological and phytochemical data suggests that all species except for $S$. wightii form 
a monophyletic group with strong bootstrap support of $82 \%$. According to the strict consensus tree of the combined analysis (Figure 5), eight monophyletic groups can be identified within the genus Stemonoporus. Twenty seven clades can be identified in all the parsimony analyses. S. gardneri, $S$. revolutus and $S$. latisepalum form a grade as sister to a large monophyletic group $\mathrm{G}$ with $73 \%$ bootstrap support. Within this large monophyletic group two sub-groups can be identified indicated as E and F. Clade F holds together S. cordifolius, S. angustisepalum and S. scaphifolius with good support (58\%) including S. angustisepalum and S. scaphifolius as a very closely knit monophyletic clade with $93 \%$ bootstrap support. The remaining clade (E) is broadly divided into two monophyletic groups (A and B). In the clade B, S. oblogifolius, S. reticulates and ST 23 form a grade. S. gracilis, S. elegans, S. lancifolius, S. nitidus and $S$. leavifolius are held together in the monophyletic group (D) and this group is strongly supported with $63 \%$ bootstrap. The remaining taxa in this clade (B); S. gilimalensis, S. rigidus and S. petiolaris form a small monophyletic group (C) within which S. rigidus and $S$. petiolaris are closely bound together by $61 \%$ bootstrap support. S. acuminatus, S. kanneliyensis,

Table 2: Flavonoid patterns in Stemonoporus Thw. Abbreviations: My - myricetin; Qu - quercetin; Km - kaempferol; Ap apigenin and $\mathrm{OG}=$ outgroup

\begin{tabular}{|c|c|c|c|c|}
\hline \multirow[t]{2}{*}{ Scientific name } & \multicolumn{3}{|c|}{ Flavonol } & \multirow{2}{*}{$\begin{array}{c}\text { Flavone } \\
\text { Ap }\end{array}$} \\
\hline & My & $\mathrm{Qu}$ & $\mathrm{Km}$ & \\
\hline ST 02 & - & + & + & + \\
\hline ST 01 & - & + & + & + \\
\hline ST 17 & - & + & - & + \\
\hline ST 16 & - & + & - & + \\
\hline ST 14 & - & + & $?$ & $?$ \\
\hline ST 09 & - & + & + & + \\
\hline ST 12 & - & + & - & + \\
\hline ST 05 & - & + & + & + \\
\hline ST 06 & - & + & + & + \\
\hline ST 07 & - & + & + & + \\
\hline ST 08 & - & + & - & - \\
\hline ST 13 & - & + & + & + \\
\hline ST 04 & - & + & - & + \\
\hline ST 21 & - & + & - & - \\
\hline ST 24 & - & + & - & + \\
\hline ST 18 & - & + & - & + \\
\hline ST 15 & - & + & - & + \\
\hline ST 03 & - & + & - & + \\
\hline ST 20 & - & + & - & + \\
\hline ST 11 & - & + & - & + \\
\hline ST 22 & - & + & + & + \\
\hline ST 10 & - & + & - & - \\
\hline ST.23 & - & + & + & + \\
\hline OG & - & + & - & - \\
\hline
\end{tabular}

S. lanceolatus and the monophyletic group containing $S$. affinis, S. scalarinervis form a grade sister to the strongly supported ( $80 \%$ bootstrap) monophyletic group (A) consisting of S. moonii, S. marginalis, S. bullatus and S. canaliculatus.

As the phytochemical data resulted only in four different chemicals the data was not analyzed independently.

\section{DISCUSSION}

\section{Phylogenetic inferences for Stemonoporus}

The results of the cladistic analysis allow the phylogenetic relationships of Stemonoporus to be viewed under a new light and provide a basis for other studies.

It is interesting to note that the combined analysis of morphological and phytochemical data does not support the monophyly of the genus. Leaving $S$. wightii, the rest of the genus is well supported with $82 \%$ of bootstrap value as a monophyletic group during the combined analysis. During the independent analysis carried out with phytochemical data, the genus was divided into three broad groups (results not given). Therefore, the phytochemical data has not supported the monophyletic clades as synapomorphies, but has only contributed for the building up of the phylogenetic relationships of the genus. Reconstruction based on a broad range of character types helps avoid possible biases among characters that may yield erroneous phylogenetic signals and also may provide resolution of relationships hitherto unresolved by separate data ${ }^{23,24}$. According to Hillis ${ }^{25}$ large data sets, in this case the combined, are not only feasible to analyze but have proven to be robust. Hillis states that although a large data set may have homoplasious characters that is because there are more characters the true phylogenetic signal will come through. The opinion of Kostermans ${ }^{2}$ that the genus be divided into two sub-genera (Sub genus Monoporandra and Sub-genus Stemonoporus) depending on the number of stamens finds no support in any of the analyses, which recognize stronger morphological characters that explain the phylogenetic relationships within the genus.

Stemonoporus wightii is recovered as the basal taxon of the genus, which is separated from the rest of the taxa by 33 character changes. The species was recognized by Thwaites in 1854 highlighting oblong to linear-oblong, apiculate leaves with rotundus to subcuneate base, lower surface rough with minute hairs, long petiole, shortly apiculate anthers and the paniculate inflorescence. Ashton ${ }^{4}$ included $S$. wightii together with Vateria wightii and Vateria ceylanica under S. ceylanicus. 
According to Kostermans' ${ }^{2}$ circumscription, Vatica wightii, Vateria wightii, S. ceylanicus and S. macrophyllus are considered as synonyms under $S$. wightii. According to the findings of the present study the species possess the largest leaves (leaf size 21-35 x 8-12 cm) among all the members of the genus. The thickly coriaceous leaves are elliptic to wide elliptic, lamina sub-bullate with sub-impressed prominulous primary, secondary veins and inter-secondary veins. The leaves have about 18-25 secondary veins, with acute-moderate and acutewide angles of origin where the upper secondary angle becomes more acute than the lower. Tertiary veins with right angle origin are percurrently, closely arranged. These leaves lack areoles but possess highly branched veinlets with a highest vein order of $8^{0}$. Its flowers are borne on panicles which attain a length of up to $18 \mathrm{~cm}$ bearing more than 25 flowers on each panicle. These are the largest inflorescences and the highest number of flowers observed among Stemonoporus. These are few of the autapomorphic characters which separate the species from the rest. The present analyses indicate that $S$. wightii also shares a set of common plesiomorphic characters in the inflorescence, size of leaves and number of flowers with Vateria copallifera. Although $S$. wightii occurs as the basal taxa close to the out-group Vateria copallifera, the two taxa never appeared as a monophyletic group in any preformed analyses. This is mainly due to the fact that $S$. wightii acquires all the synapomorphies of the genus.

Stemonoporus gardneri is resolved as the sister group to the large monophyletic clade H (Figure 5). $S$. gardneri with narrow ovate leaves which are mostly hanging down from the thick stout petioles, prominulous primary and secondary veins with acute-narrow to acutemoderate angles have percurrent pattern of tertiary veins with acute-obtuse angles. The highest vein order of the species is $7^{0}$, it lacks areoles or veinlets and the lowest secondary veins show pseudoquitriplinerved venation. The inflorescences of the species are only smaller to those of S. wightii Thw. containing up to 8-18 flowers. Further, these are the only two species $(S$. wightii and $S$. gardneri) which showed mass flowering within the genus. Morphological affinity and the phylogenetic link between S. gardneri and S. wightii are mainly due to these characters.

Specimens of the species were collected from southern and eastern slopes of the Peak Wilderness Sanctuary, between $1500 \mathrm{~m}$ and $1800 \mathrm{~m}$ of altitude and also from Morningside in the Knuckles range. Leaves of the collected specimens as well as those of the herbarium specimens (Royal Botanic Gardens, Peradeniya) studied showed considerable variation in shape, number of lateral veins and also in the leaf texture. But the flowers of all specimens were observed to be the same with thick, curved pedicels. Thwaites ${ }^{5}$ considered the inflorescence as paniculate and Trimen ${ }^{6}$ considered it to be racimiflorous. It can be considered as a mixture of the two types as described by Kostermans ${ }^{2}$. The striking differences in leaf characters were highlighted by Kostermans ${ }^{2}$ but he has stated that he is not in a position to separate the specimens collected from different geographical locations as separate entities, due to the poor condition of the material available. During the present study, which has incorporated fresh, as well as herbarium material, which are in good condition, the specimens have not divided as separate entities but rather stuck together as a single species. In Kostermans ${ }^{2}$ key to the species, he has highlighted the character elevation of the primary vein, which he thought was impressed in S. gardneri and prominulous in $S$. wightii which is a misinterpretation. It was clearly observed that in both species primary and secondary veins are prominulous on the upper leaf surface. However, the present study suggests that the two species share similarities which had not been detected by the previous workers and that the two species occur as sister groups.

Stemonoporus revolutus was found to have a large number of autapomorphic characters. The leaves with a characteristic revolute lamina and obtuse to retuse apex, strongly impressed primary vein, prominulous secondary veins, percurrent tertiary veins with acute-obtuse origin, the highest vein order of $7^{0}$, and the lack of areoles can be used as discrete characters of the species. Inflorescences of $S$. revolutus are born in groups of 5 in axillary racemes, bearing yellowish flowers with brownish lanceolate sepals which are valvate in aestivation.

Ashton ${ }^{4}$ assumed that the flowering inflorescence of S. revolutus does not exceed $4.5 \mathrm{~cm}$, and bears at most 5 flowers, and generally ramiflorous at least in fruit. But it was observed that the inflorescence of $S$. revolutus reaches a length of $5-6 \mathrm{~cm}$ and bears up to 7 flowers. The species with its unique feature in leaves and flowers is resolved separately and phylogenetically close to $S$. gardneri in the present study. Although the shape and size of the leaves and nature of the flowers seem to be quite different, detailed study of the leaf architectural feature revealed a number of similarities among the two species.

$S$. latisepalum was recognized by Kostermans ${ }^{4}$. He states that the species resembles $S$. kanneliyensis in venation and he highlights the low number of lateral veins, short, broad acumen and not impressed mid-rib in S. latisepalum as key features to separate the two. 
Moreover he states that the lateral veins do not form a marginal vein, the inflorescence paniculate and the sepals unusually broad in $S$. kanneliyensis as opposed to $S$. latisepalum. Further Kostermans ${ }^{2}$ considered $S$. latisepalum to be closely similar to $S$. affinis. But the present study revealed that the species is not phylogenetically close to either of the two species. The species is resolved as sister to the large monophyletic clade G. According to the detailed study of leaf venation, S. latisepalum nor S. kanneliyensis form a marginal vein as stated by Kostermans ${ }^{2}$. In addition to the differences in leaf shape, size and the nature of the acumen the two species also differ in the angle of secondary veins, development of areoles (lacking in S. latisepalum and present in S. kanneliyensis and $S$. affinis) and in nature of flowering. Short, bluntly acuminate sub-coriaceous leaves with slightly elevated primary and secondary veins on the upper leaf surface, percurrent pattern of tertiary veins with right angle origin and the lack of areoles and veinlets, paniculate inflorescences with small flowers are few of the apomorphic features of the species.

Monophyletic group $\mathrm{F}$ with $58 \%$ bootstrap support consists of $S$. cordifolius, S. angustisepalum and $S$. scaphifolius. These three species together with $S$. elegans were classified under the sub-genus Monoporandra by Kostermans ${ }^{2}$ considering that all four species contain 5 stamens in contrast to the $10-15$ stamens contained by the other members of Stemonoporus. Almost all the earlier workers have kept $S$. cordifolius and $S$. elegans as closely similar considering the stamens character. Further, he separated $S$. cordifolius Auct. (non Alston) and united it with $S$. affinis Auct. (non Thwaites) emphasizing the larger size of the leaves when recognizing $S$. angustisepalum. The very low number of characters used to split the species created lot of controversy.

The present study revealed that $S$. cordifolius and $S$. elegans are phylogenetically very distantly related. The two species have moved in two distantly related monophyletic groups within the genus. Although the number of stamens is a good field character, there are more distinct characters which have played an important role in the evolution of the two species. According to the present findings the reticulate pattern of tertiary veins and the lack of areoles in S. elegans as opposed to the percurrent pattern of tertiary veins and the presence of areoles in $S$. cordifolius can be considered as key characters separating the two species. S. cordifolius is found to be phylogenetically more closely related to $S$. angustisepalum and S. scaphifolius. All three species have eucamptodromous venation, stout primary veins, thick secondary veins without inter-secondary veins and well developed, oriented areoles as synapomorphies.
But the acute-obtuse angle of origin and the more acute origin on one side of the leaves of secondary veins, right angled relationship of the closely arranged tertiary veins to the mid vein act as apomorphies separating $S$. cordifolius from the other two species. In addition to the above mentioned apomorphic characters, smaller (4 -9x $2.5-4 \mathrm{~cm}$ ), narrow-ovate leaves with abruptly acuminate apex, 0.9-1.6 cm long obtuse acumen, prominulously elevated primary and secondary veins play key roles in identifying the species from the rest.

In contrast $S$. angustisepalum has much larger (10 - 17 x 5-8 cm), elliptic leaves, with deeply impressed primary, secondary and tertiary veins with bullateness in the lamina, higher number of secondary veins $(9-12)$, tertiary veins with right angled origin on both sides, and inter-secondary veins. These characters play a major role in separating $S$. angustisepalum from $S$. cordifolius. Further according to the present analyses, S. scaphifolius and $S$. angustisepalum are resolved as sister groups with strong support (93\% bootstrap). S. scaphifolius shares much of the characters with $S$. angustisepalum. Ellipticoblong shape, and acuminate nature of the thickly coriaceous leaves, sub-bullate nature of the lamina and similar type of inflorescences with small flowers containing 5 stamens are few of the synapomorphies. The major differences as cited by Kostermans are the patent, drooping, concave leaves and the less number of flowers.

S. oblongifolius, S. reticulatus and ST 23 form a grade in the monophyletic group B. Kostermans ${ }^{2}$ relates the species to $S$. gardneri considering the similar nature in fruit. The more pronounced pubescence, especially on the sepals and much shorter pedicels were regarded as discrete characters separating the two species. These two species are phylogenetically kept apart in all the parsimony analyses performed. Elliptic shaped, obtuse to shortly acuminate leaves with acute-moderate and acutewide angle of secondary veins with irregular variation, imperfect, randomly arranged areoles of S. oblongifolius contrast with narrow-ovate, abruptly shortly acuminate leaves with acute-narrow and acute-moderate angle of secondary veins where the upper angle becomes more acute than the lower and the absence of areoles of $S$. gardneri. If the flowering nature is considered, they are very different with $S$. oblongifolius showing complex clusters of flowers and $S$. gardneri with racemose to paniculate inflorescences. These characters speak as to why the two species are distantly related.

S. reticulatus as described by Thwaites; "leaves oblong to oblong lanceolate, long acuminate, base rotundus, above nitidus, below between primary veins 
obscurely reticulate - no parallel veins, long petiole; pedunculate, frequently with 1 flower". Kostermans ${ }^{2}$ splits the species into two; $S$. reticulatus and S. kanneliyensis. In the descriptions of the two species he has emphasized the following characters;

S. kanneliyensis - leaves elliptic to subovate - elliptic, abruptly acuminate, acumen very slender, sharp, base round or so, mid-rib shallowly impressed; below glossy, paler, 10-18 pairs of secondaries, inter secondaries present, fruit conical, acute; $S$. reticulatus - leaves subovate-elliptic to elliptic, conspicuously acuminate, acumen slender, obtuse, base rounded to shortly acute, mid rib prominulous, below glossy, 10 -11 pairs of lateral veins, not connected to a marginal vein, no tertiaries, fruit ovoid acute. It is evident that some of these characters overlap and thus create problems in identification. This may be a reason that Ashton ${ }^{26}$ excludes S. kanneliyensis. According to present parsimony analyses the two species are phylogenetically distant relatives with lot of morphological dissimilarities. S. reticulatus having leaves with distinctly reticulate lower surface, with moderately elevated secondary veins, conical shaped fruits and few flowered inflorescences with flowers consisting of lanceolate and ovate sepals in imbricate aestivation diverges from $S$. kanneliyensis having not distinctly reticulate venation with faintly elevated secondary veins, acute pointed shaped fruit and manyflowered inflorescence, flowers with oblong or elliptic sepals in valvate aestivation.

ST 23, which recovered as a new morphologically unique taxon (Rubasinghe et al., unpublished) is resolved as phylogenetically more closely related to $S$. reticulatus. The leaves of ST 23 are hanging, glabrous, narrow elliptic to narrow oblong in shape and are attached to a slender geniculate petiole. It has eucamptodromous venation, prominulous primary and secondary veins and also intersecondary veins. The angle of origin of secondary veins is acute-moderate, while the angle of origin of tertiary veins was observed to be acuteobtuse, with percurrent pattern and distant arrangement. Flowers developed on axillary racemes. In contrast to the autapomorphic character of the species it's closely related to $S$. reticulatus. by the presence of cone-shaped fruits with longitudinal furrows, prominulous primary and secondary veins and the two species also share similar floral characters. But they are quite different

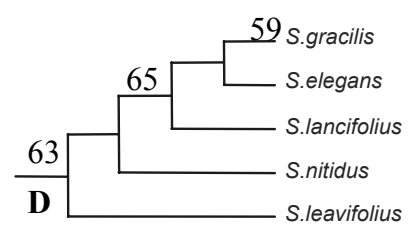

since $S$. reticulatus possesses reticulate and percurrent patterns of tertiary veins without areoles and also by the leaf morphological characters.

The monophyletic group D with a strong bootstrap support of $63 \%$ consists of $S$. gracilis, S. elegans, $S$. lancifolius, S. nitidus and S. leavifolius.

Going through the characters this group is well supported in all the analyses and according to the phylogram separated by 18 characters from the rest of the taxa. Acuminate leaf apices, obtuse-cuneate to obtuse rounded leaf bases, slightly revolute leaf margins, nature of the inflorescences are few of the unambiguous synapomorphies of the group.

S. leavifolius is recovered as the basal taxon to the rest of the group. The species has been recognized as form b of $S$. acuminatus by Trimen, which was confirmed by Ashton. But it was not divided as separate entities by both authors. Kostermans ${ }^{2}$ considering the hardly elevated spreading and less numerous lateral veins and the puberulous nature of the sepals separated the species from $S$. acuminatus. He related the species to $S$. reticulatus.

S. leavifolius is recovered as the sister group to S. nitidus in all the analyses performed with $63 \%$ of bootstrap support. S. leavifolius contains lanceolate shaped, gradually acuminate leaves where the margin is slightly revolute near the base, and with prominulous primary and secondary veins and reticulate pattern of tertiary veins lacking areoles. S. nitidus also with prominulous primary and secondary veins, slightly revolute margin near the base and reticulate pattern of tertiary veins differs from the narrow ovate shape and the abruptly acuminate nature of the leaves and the presence of areoles.

S. lancifolius is recovered as the sister group of the monophyletic group formed by $S$. elegans and $S$. gracilis. All three species have abruptly acuminate apices, slightly revolute margins, reticulate pattern of tertiary veins in their leaves and lanceolate sepals with valvate aestivation as synapomorphies.

Owing to the synapomorphies; narrow-elliptic or narrow-oblong leaves with obtuse cuneate bases, deeply impressed to channeled mid ribs, acute-moderate and acute-wide secondary angles and the lack of areoles, $S$. elegans is recovered as more closely related to $S$. lancifolius. Despite the fact that the two species possess different numbers of stamens ( $S$. elegans with 5 stamens and $S$. lancifolius with 15 stamens), differ 
in habit (S. elegans is a tree and S. gracilis has a bushy nature), number of secondary veins (5-7 in $S$. elegans, 10-12 in $S$. gracilis) these synapomorphic characters have played an important role in their phylogeny.

S. lancifolius separated from the above two species due to lanceolate shaped leaves, with obtuse normal bases, prominulous primary and secondary veins, acutemoderate angles of secondary veins and the presence of imperfect, randomly arranged areoles in the leaves.

S. petiolaris, S. rigidus and S. gilimalensis form a monophyletic group with no bootstrap support. Thwaites ${ }^{5}$ described S. petiolaris as "leaves linear-oblong, abruptly acuminate, base rotundus to sub-cuneate, above turned down, below rough, with minute hairs on lower surface, petiole long; peduncle with 1-3 flowers." Trimen ${ }^{6}$ classified the species highlighting the length of the petiole. Ashton ${ }^{4}$ considered the leaf shape, elevation of veins and the number of secondary veins. Kostermans ${ }^{2}$ separates S. petiolaris Auct. (non Thwaites) by thicker leaves with closely packed numerous secondary veins and different much longer hairs as S. scalarinervis. Trees recovered from the parsimony analysis suggest that the species is more closely related to $S$. rigidus and S. gilimalensis.

S. gilimalensis and $S$. petiolaris are linked by the prominulous primary and secondary veins, acute moderate angle of secondary veins, percurrent pattern of tertiary veins with acute-obtuse angle, imperfect, randomly arranged areoles and the distantly arranged tertiary veins. Oblong shaped abruptly shortly acuminate leaves with obtuse bases, clusters of flowers and the pedicels covered with bracteoles can be highlighted as diagnostic characters of $S$. petiolaris. Stemonoporus gilimalensis has apiculate to obtuse leaves, with upper secondary angle becoming more obtuse, elliptic, obtuse petals as distinct features.

Stemonoporus rigidus has oblanceolate to narrowovate, mucronate to obtuse, thickly coriaceous leaves with acute-narrow and acute-moderate angle of secondary veins where the upper becomes more obtuse than the lower, well developed, oriented areoles with veinlets and the closed arranged tertiaries. Flowers occurring in clusters, with many bracts and bracteoles, prominulous elevation of primary and secondary veins speak as to why the two species are closely related.

According to the parsimony analyses $S$. acuminatus has resolved as the sister group to $S$. kanneliyensis (Figure 5). S. acuminatus with narrow-oblong, acute to acuminate leaves of chartaceous texture and with rounded to obtuse bases, prominulous primary and secondary veins, percurrent pattern of tertiary veins of right angled origin on both surfaces and with imperfect, randomly arranged areoles shows closer affinity to S. kanneliyensis.

S. affinis and S. scalarinervis form a monophyletic group. The species is recovered in the monophyletic group A, containing $S$. canaliculatus, S. bullatus, $S$. marginalis, S. moonii, S. lanceolatus and S. scalarinervis. Leaves of S. affinis are characteristically held downwards with narrow, erect petioles. These elliptic, prominently abruptly acuminate leaves show clearly the well developed, oriented, areoles of distinct shapes, when viewed against light even in the fresh state. The leaves with many inter-secondary veins, which are impressed, have become corrugated at least near the basal half.

The two species (S. affinis and S. scalarinervis) are very different by much smaller leaves (7-11 x 5-7 cm), impressed mid-rib and presence of intersecondary veins, upper secondary veins becoming more acute in S. affinis and much larger leaves (21-31 x 9-13 $\mathrm{cm})$ prominulous primary veins, lack of inter-secondary veins and upper secondary angle becoming more obtuse in S. scalarinervis.

The two species are brought together by the apomorphies; acute-moderate and acute-wide angle of secondary veins, well developed, oriented areoles, congested few flowered inflorescence and the slightly ribbed, sub-globose fruits.

In the major group A, S. canaliculatus S. bullatus, S. marginalis and $S$. moonii forms a monophyletic group with strong bootstrap support $(80 \%)$. Brochidodromous venation, presence of an intra-marginal vein and loop forming branches are the unambiguous synapomorphies for the clade. Flowers developed as clusters with 1-4 flowers, with many bracts and bracteoles covering their peduncles, abruptly curved and connected secondary veins, percurrent pattern of tertiary veins, bullate to sub-bullate nature of the leaf lamina and globose to sub-globose shaped fruits are few other synapomorphic characters of the clade.

S. canaliculatus as described by Thwaites"; "leaves oblong, lanceolate to linear-lanceolate, more or less abruptly acuminate, base rotundus to sub-cuneate, above towards margin canaliculatus, below rough with minute hairs laevibusve; peduncle seapissime with 1 flower". Trimen $^{6}$ separated $S$. canaliculatus from the rest by the channeled nature of the mid-rib. Ashton ${ }^{4}$ followed the same features in his classification. Kostermans ${ }^{2}$ separated the species into; $S$. canaliculatus, S. bullatus 
and S. marginalis emphasizing on leaf morphological characters (leaf size, number of lateral veins and pattern of secondary veins). According to the present analyses, the three species are phylogenetically closely related.

S. bullatus and S. marginalis have strongly impressed primary and secondary veins on the upper leaf surface with a continuous prominent marginal vein making the leaves strongly bullate. Inter-secondary veins are prominent in both taxa. Though they possess much similar features several characters were observed which were unique to each. The angle of origin of secondary veins in $S$. marginalis are right-angles to the mid vein while those in S. bullatus are acute-moderate. The angle of loop forming branches of the two species showed differences; that of $S$. marginalis are obtuse while that of S. bullatus are right-angled. The leaves of S. marginalis are much larger (36-45 x 13-19 cm) and has much more secondary veins (28-35) which are deeply impressed near the mid vein making the leaf corrugated, whereas the leaves of $S$. bullatus ranges between 21-37 x 7.5-12 $\mathrm{cm}$ with less number of secondary veins (16-20) and the leaves are prominently bullate but not corrugate.

In contrast to the strongly impressed primary and secondary veins of $S$. bullatus and $S$. marginalis primary and secondary veins of $S$. canaliculatus are prominulous to sub-impressed and the leaves are sub-bullate. The secondary veins are abruptly curved and connected to form a marginal vein but the marginal vein is not continuous due to few secondaries losing their identity near the margin. Although closely related to $S$. bullatus it has much smaller leaves (10-19 x 4-7 cm), and a low number of secondary veins (9-13). The origin of tertiary veins in $S$. canaliculatus is right angled while that in $S$. bullatus is acute-obtuse. In contrast to the presence of prominent inter-secondary veins are in S. bullatus, intersecondary veins absent or very rare in $S$. canaliculatus.

S. moonii is recovered as sister to $S$. canaliculatus, $S$. bullatus and $S$. marginalis, mainly owing to the presence of a marginal vein, presence of inter-secondary veins, flowering nature etc. In addition to the above-mentioned characters $S$. moonii has very long slender persistent stipules and linear long hairy bracts as autapomorphies. Specimens of the species were first collected by Moon around 1820-1825. Thwaites observing the specimens collected by Moon, found that this was a Stemonoporus with the correct number of stamens, etc., but because of the peculiar long numerous stipules, included it in Stemonoporus with an interrogation mark $^{2}$. Ashton ${ }^{26}$ observing a sterile specimen concluded that this was not Stemonoporus but likely to be Stericulaceae or Euphorbiaceae. But once the species was re-discovered by Kostermans and I.A.U.N. Gunatilleke in 1992 it was confirmed as a Stemonoporus ${ }^{2}$.

One of the most characteristic features of this taxon is its possession of two types of venation in the same leaf, i.e. half the leaf is composed of brochidodromous venation while the other half is composed of eucamptodromous venation (it can be on either side of the leaf or as upper and lower halves of the leaf). Areoles are much larger than the other taxa of this clade $(2.0-2.5 \mathrm{~mm})$. Both reticulate and percurrent patterns of tertiaries were observed in the leaves. Flowers consisted of 10 -13 (mainly 10) stamens, and they were observed to be the largest flowers of the genus with a diameter of 2.5-2.6 $\mathrm{cm}$. The species was also found to be unique by being a spindly tree with a thin bark.

S. lanceolatus is recovered as the sister group to the clade containing S. canaliculatus, S. bullatus, S. marginalis and $S$. moonii. Narrow-elliptic leaves of $S$. lanceolatus has eucamptodromous venation, where the secondary veins are closely placed. These secondaries are curved abruptly like in the $S$. canaliculatus, but they lose their identity near the margin. Primary and secondary veins are prominulous above. Tertiary veins which are acuteobtuse in origin, are very closely placed, and show both oblique and right-angle relationships to the primary vein. Areoles are much smaller in diameter $(1.5 \mathrm{~mm})$.

Flowers born as 1-4 clusters and possess prominent bracts which are similar to those of $S$. moonii in shape and colour. Development of flowers, nature of bracts, and pedicels covered by bracts have positioned the species as sister to the group containing $S$. canaliculatus, S. bullatus, S. marginalis and S. moonii. But the peculiar arrangement of tertiaries and secondaries operate as autapomorphies in separating the species.

\section{Morphological data in phylogeny reconstruction}

The aim of working on evolutionary history of a group of species is to generate robust phylogenetic hypothesis for the taxon. The wealth of new molecular data raises the question: what should be the role of morphological data in phylogeny reconstruction? Some suggest that morphological data should not be used to build trees or new morphological data should not be included in phylogeny reconstruction ${ }^{27}$.

Although, since the molecular revolution in systematics, large amounts of new data have been generated by finding and sequencing new gene regions, positive effects of combining morphological data with molecular data have been reported with many studies ${ }^{28,29}$. 
In most cases, morphology plays a critical role in defining species in phylogenetic studies ${ }^{29}$.

In order to evaluate different classification schemes, and to use the classification as a framework for evolutionary studies, phylogenetic analyses are necessary. In this context, neither molecular nor morphological data are superior. Both types of data are useful for phylogenetic reconstruction. When a phylogeny based on molecular data is compared with an "accepted" classification, the latter is often rejected because most classifications today are based on phenetic similarity and do not reflect the phylogeny. However, this does not mean that morphological data should be dismissed as inferior for phylogenetic reconstruction. With cladistic analysis, both molecular and morphological data may be useful and complementary in phylogenetic reconstruction ${ }^{30},{ }^{31}$. Many morphological studies aimed at identifying sister group hierarchies have been successful and shown congruence with molecular analysis ${ }^{28-32}$. These studies have revealed how well systematic relationships based on morphological and ecological characters predict genetic relationships between taxa, especially those pertinent to conservation prioritization. Thus the secret lies behind the handling of morphological data (proper coding of homologous characters and continuous data) in phylogenetic analysis.

Wiens, ${ }^{27}$ in his study points out many reasons to continue to do morphological phylogenetics. One of the most compelling reasons to continue to collect morphological data long into the future is to resolve the phylogenetic relationships of those many taxa that are extant but may still be very difficult to include in molecular studies $^{27}$. Many species remain known from a single specimen that was collected decades ago or only known from a limited number of specimens or literature as in some species of Stemonoporus (S. nitidus and $S$. scaphifolius) so as to make obtaining molecular data very difficult. During the present study, it was observed that the habitats of several species of Stemonoporus are very disturbed either due to deforestation or degradation and therefore most species occur as localized patches. Many places that would have been "wet and wettest parts" ten years back (as discussed in Ashton ${ }^{4}$ and Kostermans ${ }^{2}$ ) seem to have changed with time. Very little regeneration was observed with many species; except in well protected sites such as the Sinharaja and Kanneliya. They all prefer their own specially defined ecological niche.

Though, in the past they had occurred in large numbers, at present the populations have declined. $S$. marginalis, as csited by Kostermans ${ }^{2}$ 'gregarious on low broad ridges in mixed Dipterocarp forest', was found only in a small patch at Neluwa-Pelawatta new road as most of the forest patches have been cleared for tea cultivation and other purposes. S. affinis occurs only in the submontane zone of the Knuckles Range (north of the Central Massif), where it is rare and restricted. The populations in the Knuckles region are deteriorating and the individuals at the Corbett's Gap area are quite old. There is no evidence of regeneration. Several other species have highly localized distributions. Species such as $S$. moonii is known only from an inland marsh forest in Bulatsinhala and S. petiolaris occurs near a huge rock in a mountain top close to Kitulgala/Yatiyantota area and is represented by a very few number of individuals. The population is in very poor regeneration conditions. Perhaps this site would have been wetter in the past than now and with the destruction of the normal watercourses the area would have become drier.

S. gracilis is only known from an area along a tributary of the Kelani River, in the Kitulgala regions. These populations are more or less growing without any major disturbances. S. latisepalum is also known only from its type locality Peak Wilderness Sanctuary. $S$. nitidus is only known from one specimen collected in 1855 (Thwaites's collection: C.P. 3483), which is deposited at the National Herbarium, that bears one immature flower. Figure 4 shows the distribution of some species of Stemonoporus.

Given present technology, the only way that we may know anything about the relationships of theses species is through phylogenetic analysis of morphology. Until a stage is reached where all molecular phylogenies are reconstructed without error, it is still important to have rigorous, morphology-based phylogenies as a "reality check" for molecular results ${ }^{27,33}$. There are many factors like long-branch attraction ${ }^{34}$, deviations between gene and species, trees and more mundane problems such as contamination and misidentification of specimens, that may cause molecular analyses to reconstruct clades that are both incorrect and statistically well-supported. Comparing molecular results to rigorous morphologybased phylogenies can help prevent being misled in these cases $^{27}$. Despite the many advantages of molecular data, it is absolutely critical that systematists continue to be trained in morphological systematics as well, particularly for poorly known groups ${ }^{27}$.

As discussed in previous studies ${ }^{31,35}$ poorly resolved taxonomies have a negative impact on conservation assessments. The lack of systematic knowledge for potentially threatened taxa thus precludes effective conservation. In the light of the present study the endemic genus Stemonoporus encompasses 27 species with distinct morphological variations. This includes a 
new species that has not been recognized during previous studies. Controversial ideas regarding the species limits of the genus are completely resolved and the phylogenetic relationships are discovered by morphological data that consist of distinct, diagnostic characters. Several additional characters have been identified to describe the recognized species. This information can play a crucial role in the identification and conservation of Stemonoporus Thw.; the most species-rich endemic dipterocarp genus in Sri Lanka.

\section{Acknowledgement}

The authors thank the National Science Foundation, Sri Lanka and the International Foundation for Science, Sweden, for financial assistance the Forest Department and the Wildlife Department for granting permission to collect specimens and the National Herbarium, Royal Botanic Gardens Peradeniya.

\section{References}

1. Senaratna L.K. (2001). A Checklist of the Flowering Plants of Sri Lanka. MAB Checklist and Hand Book Series: 22. P.451. National Science Foundation, 47/5, Maitland Place, Colombo 7.

2. Kostermans A.J.G.H. (1992). A Hand Book of the Dipterocarpaceae of Sri Lanka. Wildlife Heritage Trust of Sri Lanka, 95, Lotta Rode, Colombo 08.

3. International Union for Conservation of Nature (2000). The 1999 List of Threatened Fauna and Flora of Sri Lanka. pp. 114. ICUN, Horton Place, Colombo 07.

4. Ashton P.H. (1980). Dipterocarpaceae. In: A Revised Hand Book to The Flora of Ceylon. (Eds. M.D. Dassanayake \& F.R. Fosberg) 1: 404 - 418.

5. Thwaites G.H.K. (1864). Enumeratio Plantarum Zeylanicae: an Enumeration of Ceylon Plants. pp. 11-12 Dalau \& Co. London.

6. Trimen H. (1893). A Handbook to the Flora of Ceylon, Part 3. pp. 436 - 437. Bishen Singh Mahendra Pal Singh, New Connaught Place, Dehra Dun, India.

7. Rubasinghe S.C.K., Yakandawala D.M.D. \& Wijesundara D.S.A. (2005). A preliminary study on species limits of the endemic genus Stemonoporus (Dipterocarpaceae) using morphological data. Proceedings of the Peradeniya University Research Sessions, Peradeniya. (10): 92.

8. Ashton P.S. \& Gunatilleke C.V.S. (1987). New light on the plant geography of Ceylon 1. Historical plant geography. Journal of Biogeography 14(3): 249 - 285.

9. Judd W.S., Campbell C.S., Kellogg E.A. \& Donoghue M.J. (2002). Plant Systematics: A Phylogenetic Approach. pp. 15-45. Sinauer Associates, Ind. Publishers, Sunderland, Massachussets U.S.A.

10. Stuessy T.F. (1990). Plant Taxonomy: The Systemic Evaluation of Comparative Data. p.405. Columbia University Press, New York.
11. Hegnauer R. (1986). Phytochemistry and plant taxonomy - an essay on the chemotaxonomy of higher plants. Phytochemistry 25(7):119-1535.

12. Harborne J.B. (1984). Phytochemical methods - a guide to modern techniques of plant analysis. p. 302 Chapman \& Hall, London.

13. Erdtman H. (1963). Some aspects of chemotaxonomy. In: Chemical Plant Taxonomy (Ed. T. Swain) pp. $89-125$, Academic Press, London.

14. Harborne J.B. (1975). Biochemical systematics of flavonoids. In: The Flavonoids (Eds. J.B. Harborne, T.J. Mabry \& H. Mabry). pp. 1056-1095. Chapman and Hall, London.

15. Soltis D.E., Soltis P.S. \& Doyle J.J. (1998). Molecular Systematic of Plants II: DNA Sequencing. p.555 Kluwer Academic Press, Boston Massachussets,USA.

16. Dayanandan S., Ashton P., Williams S.M. \& Primack R.B. (1999). Phylogeny of the tropical tree family Dipterocarpaceae based on nucleotide sequences of the chloroplast rbcL gene. American Journal of Botany 86 (8): 1182-1190.

17. Markham K.R. (1982). Techniques of Flavonoid Identification. pp. 8-28. Academic Press, London.

18. Ribereau-Gayon P. (1972). Plant Phenolics. pp. 7-30 Hafner, New York.

19. Bate-Smith E.C. \& Swain T. (1965). Recent developments in the chemotaxonomy of flavonoid compounds. Lloydia 28: $313-331$.

20. Kitching I.J., Forey P.L., Humphries C.J. \& Williams D.M. (1998). Cladistics: The Theory and Practice of Parsimony Analysis. P. 197. The Systematics Association Publication 11. Oxford University Press, UK.

21. Swofford D.L. (1998). PAUP*: Phylogenetic analysis using parsimony (and other methods) Beta version 4.0. Computer software, Sinauer Associates, Sunderland, Massachusetts, USA.

22. Maddison W.P \& Maddison D.R. (1998). MacClade: analysis of phylogeny and character evolution, version 3. Sinauer Associates Inc. Sunderland, Massachusetts, USA.

23. Kluge A.G. \& Wolf A.J. (1993). Cladistics: what 's' in a word? Cladistics 9: 183-199.

24. Nixon C.N. \& Carpenter J.M. (1993). On outgroups. Cladistics 9: 413 - 426.

25. Hillis D.M. (1996). Inferring complex phylogenies. Nature 383: $130-131$.

26. Ashton P.S. (1982). Dipterocarpaceae. Flora Malesiana Series I. 9(2):237-252.

27. Weins J.J. (2004). The role of morphological data in phylogeny reconstruction. Systematic Biology 53(4): $653-661$.

28. Simonsen T.J., Wahlberg N., Brower A.V.Z. \& de Jong R. (2006). Morphology, molecules and Fritillaries: approaching a stable phylogeny forArgynnini(Lepidoptera: Nymphalidae). Insect Systematics and Evolution 37:405418.

29. Nozaki H., Ott F.D. \& Coleman A.W. (2006). Morphology, molecular phylogeny and taxonomy of two new species of Pleodorina (Volvocaceae, Chlorophyceae). Journal of Phycology 42: 1072 - 1080. 
30. Schulmeister S. (2003). Review of morphological evidence on the phylogeny of basal Hymenoptera (Insecta), with a discussion of the ordering of characters. Biological Journal of the Linnaean Society 79: 209 - 243.

31. Rubinoff D. \& Sperling F.A.H. (2004). Mitochondrial DNA sequence, morphology and ecology yield contrasting conservation implications for two threatened buckmoths (Hemieuca; Satumiidae). Biological Conservations 118: 341-351.

32. Bremer B. (1992). Phylogeny of the Rubiaceae (Chiococceae) based on molecular and morphological data-useful approaches for classification and comparative ecology. Annals of Missouri Botanical Garden 79(2):380 $-387$.

33. Doyle J.J. (1992). Gene trees and species trees: molecular systematics as one-character taxonomy. Systematic Botany 17: 144-163.

34. Hollingsworth B.D. (1998). Systematics of chuckwallas (Sauromalus) with a phyllogenetic analysis of other iguanid lizards. Herpetological Monographs 12:38-191.

35. Bacon C.D. \& Bailey C.D. (2006). Taxonomy and Conservation: A case study from Chamaedorea alternans. Annals of Botany 98:755-763.

Appendix 1: Qualitative and quantitative characters assessed from the specimens of Stemonporus Thw. and Vateria (Retz.) Alston. Quantitative characyers were measured in centimetres.

\section{Leaf characters}

1) Habit

2) Branch-let nature

3) Orientation of leaves

4) Arrangement of leaves

5) Nature of the first leaves

6) Length of the leaf blade

7) Width of the leaf blade

8) Ratio: length / width of the leaf blade

9) Lamina shape

10) Shape of the leaf apex

11) Origin of leaf acumen

12) Length of the leaf acumen

13) Nature of the acumen

14) Variability of leaf base shape

15) Shape of the leaf base

16) Shape of the leaf margin

17) Leaf texture

18) Lamina nature

19) Petiole width

20) Petiole apex

21) Petiole length

22) Petiole nature

23) Presence of persistent stipules

24) Presence of an intra-marginal vein

25) Nature of the intra-marginal vein

26) Number of secondary veins

27) Type of venation

28) Width of the primary vein

29) Course of the primary vein

30) Elevation of the primary vein on upper leaf surface

31) Angle of origin of secondary veins

32) Variation in angle of origin of secondary veins

33) Relative thickness of secondary veins

34) Course of secondary veins
35) Elevation of secondary veins on upper leaf surface

36) Presence of loop forming branches

37) Behaviour of loop forming branches

38) Presence of inter-secondary veins

39) Pattern of tertiary veins

40) Angle of origin of tertiary veins

41) Course of tertiary veins

42) Relationship to mid-vein

43) Variation in angle of tertiary veins

44) Arrangement of tertiary veins

45) Highest vein order of the leaf

46) Marginal ultimate venation

47) Presence of areoles

48) Arrangement of areoles

49) Shape of areoles

50) Size of areoles

51) Presence of veinlets

\section{Characters of flowers and inflorescences}

52) Phenology

53) Nature of flowering

54) Inflorescence type

55) Length of the inflorescence

56) Width of the peduncle

57) Length of the peduncle

58) Width of the pedicel

59) Length of the pedicel

60) Pedicel nature

61) Colour of the pedicel

62) Presence of bracteoles covering the pedicel

63) Nature of bracts

64) Size of bracts

65) Number of flowers

66) Diametre of the flower

67) Colour of flowers 
68) Aestivation of sepals

69) Variability of sepal shape

70) Shape of sepals

71) Color of sepals

72) Length of the sepal

73) Shape of the ovary

74) Length of the style

75) Nature of the style

76) Nature of the terminal bud

77) Length of the terminal bud

78) Presence of a distinct staminal cone

79) Number of stamens

80) Number of staminal rows

81) Length of the stamens

82) Length of the anthers
83) Presence of a connectival appendage

84) Nature of anther opening

85) Presence of staminal trichomes

86) Type of trichomes

87) Shape of the fruit

88) Texture of the fruit

89) Dehiscence of the fruit

90) Tree nature

\section{Chemical characters}

91) Quercetin

92) Myricetin

93) Kaempferol

94) Apigenin 